\title{
Der elektronische Mensch, Medium und Botschaft - \\ Szenenwechsel für Marshall McLuhan?
}

von Hermann Boventer

Wenn von einem Wissenschaftler unserer Zeit gesagt werden kann, er sei mit einer einzigen Formel weltberühmt geworden, dann gilt das von dem kanadischen Professor Marshall McLuhan und dessen Motto: Das Medium ist die Botschaft. Es gibt noch ein paar andere prägnante Formulierungen von ihm, etwa seine hartnäckige Behauptung, die elektronische Revolution mache aus unserer Welt ein "Dorf“, aber keine seiner formelhaften Behauptungen fand eine solche Verarbeitung wie die Gleichung von Medium und Botschaft. Das weltweite „Ankommen“ dieser Formel, als ob es sich um einen Zauberspruch handelt, die geheimnisvolle Welt der Medien und ihrer Wirkungen aufzuschließen, wäre schon für sich genommen eine Untersuchung wert, woher die übergroßen Erwartungshaltungen stammen und warum man überhaupt auf solche Erklärungsversuche eines "Kommunikationswissenschaftlers" eingeht. Hat die gängige Wissenschaftszunft dieses Erwartungspotential unterschätzt oder bisher nicht richtig zu nutzen verstanden? Zehn Jahre lang, zwischen 1962 und 1972, erreichte McLuhan mit seinen Ideen und seinem Auftreten eine bis dahin in seinem Wissenschaftszweig nicht gekannte Popularität. Von einigen zum Propheten des elektronischen Zeitalters gemacht, von anderen als Scharlatan verdächtigt, dessen Thesen nicht nur widersprüchlich, sondern unseriös und marktschreierisch seien, lag die Einmaligkeit seines Erfolgs wohl in der Radikalität des Versuchs, die Welt der Massenmedien in einer großen „Zusammenschau“ zu humanisieren und hieraus Folgerungen für eine universelle Medienkultur abzuleiten, wie man sich als Mensch und Zeitgenosse ihren Herausforderungen $\mathrm{zu}$ stellen habe.

Der Versuch, um es vorwegzunehmen, ist nicht geglückt. Um Marshall McLuhans Botschaft ist es still geworden. „Messianismus und Wissenschaft" vermengten sich in unzulässiger Weise, rezensierte Ulrich Saxer bereits 1968, als der McLuhan-Kult seinem Höhepunkt zustrebte und „der gedankliche und kommunikative Gestus seines immer entschlossener zur universellen Gesamtschau sich ausweitenden Werkes" erst in Umrissen erkennbar geworden war. "Soll Massenkommunikation der Menschheit wirklich zum Heile gereichen, wird sie wohl kaum McLuhans Botschaft erhören dürfen", so endete Saxer damals seine überaus skeptische Würdigung. Sieben Jahre später endete Heinz Buddemeier einen Aufsatz über die Medienphilosophie McLuhans mit dem Hinweis, die Beschäftigung mit McLuhan habe deutlich gemacht, daß seine Gefolgschaft nicht zerstreut werden könne, indem man die in den Theorien steckenden Denkfehler aufdeckt. „McLuhan und Leute wie er erfüllen eine Funktion, und wer dagegen etwas tun will, darf nicht dabei stehenbleiben, Fehler aufzudecken; er muß zugleich Antworten anbieten auf jene Fragen, um deren Beantwortung willen McLuhan Gehör findet" ${ }^{\text {"2 }}$

Dr. phil. Hermann Boventer, Bensberg, ist freier Publizist, Vorsitzender der Gesellschaft Katholischer Publizisten Deutschlands, Lehrbeauftragter für politische Pädagogik an der Universität Bonn. 
McLuhan ist am 31. Dezember 1980 in Toronto gestorben. Rückblickend läßt sich feststellen, daß seine Publizität nicht gehalten hat, was sie einmal zu versprechen schien, daß aber vor allem sein Werk keine soliden Fundamente gelegt hat, auf denen sich weiterbauen läßt. Dennoch, der Versuch einer medienphilosophischen Gesamtschau, die sich nicht von vornherein ins Abseits zur empirischen Kommunikationswissenschaft stellt und deren Erkenntnisse aufzugreifen sucht, bleibt auch heute aktuell. Auf diesem Horizont des Bemühens um einen interdisziplinären Brückenschlag scheint mir die Rezeption von McLuhan und seiner Interpretation der Medienkultur trotz aller Extravaganz nicht ans Ende gelangt zu sein. Mit spöttischem Unterton gedenkt Winfried B. Lerg des gerade verstorbenen McLuhan. „Seine Thesen sind allenfalls zu fühlen, aber nicht zu erkennen", meint der Empiriker nicht ohne Grund". War es das, was McLuhans Fragestellungen so populär gemacht hat? Der Alltag der Massenmedien im Leben der Menschen hat oft so viel mehr zu tun mit praktischen Gefühlen als mit theoretischer Erkenntnis; das wäre immerhin zu bedenken bei der Rezeption von McLuhan. Was sich der Wissenschaft als "die Erkenntniswirklichkeit" anbietet, hat McLuhan oft mit verächtlicher Geste beiseitegeschoben, den Menschen andere Wirklichkeiten vorzuweisen, die sie im persönlichen Sinne „angehen“. Gibt ihnen die Wissenschaft Steine statt Brot? Ebenfalls in einem Nachruf schreibt Otto B. Roegele, daß sich inzwischen ein gewisser Wechsel der Szene in der Einschätzung von McLuhans populärer Wissenschaft von den "magischen Kanälen" vollzogen habe. Der Lärm um ihn sei verstummt, aber die Wissenschaft habe einige Beobachtungen gemacht, die McLuhans Deutungen und Voraussagen bestätigen: "Je allgemeiner die Verbreitung des Fernsehens in der Welt wird, um so deutlicher läßt sich auch erkennen, daß es die Welt nicht unerheblich verändert ${ }^{* 4}$. Gerade dies, welche verändernden Wirkungen nämlich von den neuen Medien auf unsere Denk- und Kulturmuster ausgehen, ist eine Kernfrage in McLuhans Gedankengängen gewesen. Diese Frage steht auch gegenwärtig im Mittelpunkt der medienpolitischen Debatten in der Bundesrepublik Deutschland, womit man teilweise eine Diskussion nachvollzieht, die sich im Gefolge von McLuhan schon einmal ergeben hat - und übrigens in den USA jetzt nach dem Tod von McLuhan neuen Auftrieb zu erhalten scheint.

\section{Fachwissenschaftlich ein Outsider}

Wer war Marshall McLuhan? 1911 im westlichen Kanada geboren, studierte er Ingenieurwissenschaft und dann Literatur, zuerst in Manitoba, dann im englischen Cambridge in den späten dreißiger Jahren, wo er mit Werken von K. G. Chesterton Bekanntschaft machte und zum Katholizismus konvertierte. Vor allem James Joyce hatte es ihm angetan. Über den Symbolismus kam er auf die stilistischen Parodien eines Thomas Nashe, der als Autor im Elisabethanischen Zeitalter „einen großen Appetit für Worte und ihre wortspielerischen Möglichkeiten" zeigte und die Fähigkeit besaß, sie „auf treffsichere Arabesken zu komprimieren“. Mit dieser Kennzeichnung von Thomas Nashe, über den McLuhan 1943 in Cambridge promovierte, hat er seine eigene Vorliebe für eine gewisse Doppelbödigkeit der Worte und der Sprache getrof$\mathrm{fen}^{5}$. Er kehrte nach Amerika zurück, lehrte an der Jesuiten-Universität von St. Louis und seit 1946 als Literaturwissenschaftler an der Universität von Toronto in einem von ihm geleiteten "Center for Culture and Technology", das sich der Medienforschung zuwandte. Fachwissenschaftlich blieb er ein Outsider, ja für manchen ein „enfant terrible“. Persönlich gab er ungern Auskünfte über seine Person und wissenschaftliche Entwicklung. In Toronto lebte er als Vater von sechs Kindern in einem bescheidenen Haus. 
Neben Hunderten von Zeitschriftenartikeln sind es vor allem vier Buchveröffentlichungen, die seinen Ruhm begründeten. Zuerst wenig beachtet, veröffentlichte er im Jahre 1951 „The Mechanical Bride: Folklore of Industrial Man“. Er analysiert Reklametexte aus den Massenmedien. Er zieht literarische, anthropologische und sozialpsychologische Erkenntnisse heran, die Ausbeutung der menschlichen Wunsch- und Traumregungen für kommerzielle Zwecke offenzulegen und eine Art „Psychoanalyse“ der industriellen Massenkultur zu entwickeln. McLuhan beläßt es aber nicht bei den zerstörerischen Wirkungen der herabwürdigenden Inhalte, sondern identifiziert gewisse Formelemente und Strukturen in diesen Medien, die mit der avantgardistischen Literatur und Kunst korrespondieren und dem Menschen neue Entwicklungen verheißen. Die Trennung von Inhalt (content, message) und Form (medium) charakterisiert fortan das Vorgehen McLuhans, wobei ihm die formalen Aspekte vorrangig erscheinen und sie sich schließlich in dem berühmten Satz "The medium is the message" verdichten.

Es ist schwierig und fast unmöglich, eine Summe der McLuhan'schen Ideen zu geben, weil der Autor oft anti-logisch vorgeht, sich begrifflich im Kreis bewegt und wie ein Künstler nicht darum kümmert, ob seine Hypothesen auch wissenschaftlich haltbar seien. Die Kommunikationswissenschaftler, äußerte er sich herablassend, hätten sich hauptsächlich mit Problemen der Kodierung von Informationseinheiten, mit dem Entwurf von Signalsystemen und anderem, was bereits bekannt sei, befaßt. Ihm komme es auf die einzigartigen Erfahrungen der Menschen an, wie man die Massengesellschaft mittels der Medien an ihren Erkenntnissen und Entdeckungen teilhaben läßt, „,indem wir allgemein übliche Worte und Metaphern etwa so wie Humoristen und Künstler mit bewußter Ubertreibung als, Sonden' benützen, um neuartige Situationen zu erkunden, um zu beobachten, was dann geschieht, und nach Umkehrvorgängen Ausschau halten "B.So baut er aus "Tatsachen" ein Mosaik der Beweisführung und trägt sie zur Erforschung bisher unbekannter Auswirkungen der Massenmedien aus möglichst vielen Disziplinen zusammen - eine Methode, die irritiert und berechtigte Zweifel offenläßt.

1962 bringt McLuhan sein zweites Buch „The Gutenberg Galaxy: The Making of Typographic Man" heraus, wohl sein bestes und am meisten kohärentes Buch, das ihn auf einen Schlag berühmt machte. Zwei Jahre später, 1964, folgt „Unterstanding Media: The Extensions of Man“. Teilweise gibt er sich als Prophet „in der Erforschung jener Veränderungen, die sowohl in unserer individuellen Sinneswelt als auch in den weltweiten Gesellschaftsstrukturen durch die wachsende Beschleunigung und das ständige Trommelfeuer des multimedialen Informationsflusses ebenso hervorgerufen werden wie durch den damit verbundenen Zusammenprall alter und neuer, durch neue Technologien geschaffener Milieus ${ }^{\text {"7 }}$. Das Buch findet reißenden Absatz, sieht sich der Leser doch in einer welterklärenden Futurologie gespiegelt und glaubt Antworten auf rätselhafte Fragen in einer zunehmend medienabhängig gewordenen $\mathrm{Ge}-$ sellschaft zu erhalten. McLuhans vierte Buchveröffentlichung „The Medium ist the Massage: An Inventory of Effects" vom Jahre 1967 verdeutlicht, illustriert und popularisiert noch einmal seine Grundpositionen, hier humorvoll - seine Bücher entbehren nicht gelegentlicher Karikatur und des Witzes - eingeleitet mit dem Wortspiel von "message“ und "massage“.

\section{Das Alphabet und Gutenberg}

Wie lassen sich nun diese Grundpositionen mit dem formelhaften Leitmotiv „The medium is the message ${ }^{\kappa}$ in Kurzform darstellen? Wir wählen drei Schwerpunkte aus, 
einmal das über die Sinne vermittelte Erfahrungsvermögen des Menschen, wie McLuhan es zu den Medien in Beziehung setzt; sodann die Evolution der Medien und Kommunikationsformen bis ins elektronische Zeitalter hinein; schließlich besondere Probleme der Kommunikation mit Menschen mittels Medien im Spannungsgefüge von Inhalt und Medium.

Nach McLuhans Auffassung hat jede Kultur eine sensorische Neigung oder Präferenz aufzuweisen, die ihr verborgenes Milieu oder Umfeld (environment) ausmacht. McLuhan spricht von der allumfassenden „Grundlage“, die durch solche Präferenzen konstituiert wird und die jeweilige "Gestalt" des Menschen bestimmt. Die kulturanthropologische Sicht wird bei McLuhan durch wahrnehmungspsychologische Erkenntnisse ergänzt, die besagen, daß in jedem Akt eigener Bewußtheit und Erfahrung die verschiedenen Wahrnehmungsstränge unserer Sinnesorgane - Auge, Ohr, Tastsinn, Geschmack, Geruch - zusammenfließen, und zwar simultan. Wie läßt sich die sensorische Erfahrung vermitteln? Das Phänomen der Kommunikation ist für McLuhan in seinem Denken stets das zentrale Problem. Dabei kommt ihm die Anthropologie zu Hilfe, die etwa bei primitiven Völkern auf den Einfluß wechselnder gesellschaftlicher Gepflogenheiten und Kulturformen - „stumme Sprache ${ }^{\alpha}$ - auf die bewußten und unbewußten Formen der zwischenmenschlichen Kommunikation hinweist. McLuhan fragt nach den "starken Auswirkungen der Kommunikationsmedien selbst im Sinne einer Beeinflussung der Sinneswelt - der Kommunikationspräferenzen - sowohl der Individuen als auch der Gesellschaften "».

Hier ist zu erläutern, was McLuhan unter „Extensions of Man“ versteht. Er hält sämtliche Kommunikationsmedien - Sprache, Schrift, Druck, Telegraf, Telefon, Fernsehen usw. - für technische Erweiterungen eines oder mehrerer Sinne oder Fähigkeiten des Menschen. Die Steinaxt ersetzt die Hand, die Maschine eine Vielzahl körperlicher Verrichtungen, das Radio „erweitert“ Stimme und Ohr. Im elektronischen Zeitalter ist es dem Menschen sogar gelungen, technologisch über die neuen Medien sein zentrales Nervensystem zu objektivieren mittels eines Informations- und Kommunikationsmilieus, das weltumspannend ist und „die technologische Simulation des Bewußtseins ${ }^{\kappa \theta}$ hervorbringt. Hier wird der Autor von seinen eigenen Hypothesen in eine "dichterische Vision" davongetragen, indem er, wozu er sich selbst bekennt, wie die Künster oder Erfinder sein Suchen mit den tatsächlichen oder erwünschten Wirkungen beginnt ${ }^{10}$. Andererseits ist es nicht nur Utopia, daß die Kybernetik und die Neurophysiologie voneinander profitieren und sich in manchen Erkenntnissen stüizen.

Bevor wir zu der Frage zurückkehren, wie durch die Neuordnung der Muster der Sinneskorrelation, der Sinnesreaktionen und der sensorischen Tendenzen über ein neues Medium unser psychisches und gesellschaftliches Leben gestaltet wird, ist ein Verweis auf die historischen Entwicklungsstufen, die der Mensch bis zum elektronischen Zeitalter durchlaufen hat, fällig geworden. McLuhan setzt eine präliterarische Ara der Menschheitsentwicklung voraus, in welcher der Mensch, wenn er überleben wollte, ein ausgewogenes Ensemble seines Sensoriums zur Geltung bringen mußte. Der Mensch erscheint im „Urzustand“, unverdorben von zivilisatorischer Deformation. Nicht ohne Grund hat man McLuhan eine Vorliebe für das Archaische, das Primitive vorgeworfen. So sei auch sein Hinweis zu bewerten, die Elektronik mache die ganze Zivilisation wieder zu einem "Dorf“, allerdings jetzt von globalen Ausmaßen, doch angelehnt an das Modell primitiver Stammeskulturen - „tribal culture in a global village" - aus eben jener ersten Entwicklungsstufe der Menschheit, in der sich alle Sinneskräfte noch ungebrochen entfalten konnten. 
Der "Sündenfall“ fällt mit dem Eintritt des Menschen in eine Ära der symbolischen Kommunikation zusammen, von den ersten Höhlenzeichnungen bis zur Erfindung des Alphabets. Das Auditive, das in den Stammeskulturen der präliterarischen Epoche sehr stark ausgeprägt war, wird zugunsten der visuellen Orientierung zurückgedrängt. Die phonetische Schrift, aber vor allem das Druckmedium - als erstes und „klassisches" Massenmedium - übertragen die auditiven Ausdrucksformen in visuelle. Das Alphabet und Gutenberg haben es möglich gemacht, daß der Mensch jetzt an kommunikativen Akten partizipiert, ohne auf die Gegenwart anderer Menschen angewiesen zu sein. Die Kultur individualisiert und privatisiert sich zu einem linear-eindimensionalen Bewußtsein - analytisch, aufsplitternd, spezialisierend, zentralistisch.

So kommt es zur Schaffung des „Typographischen Menschen“ in der "Gutenberg Galaxis" und zu den Voraussetzungen des Maschinenzeitalters. Kommunikation nimmt einen massenhaften Charakter an, Buchstaben und "Bücherweisheit" usurpieren den Modus der Wirklichkeitserfassung und was an Gefühlen vermittelt wird. Erst die neuen elektronischen Medien bringen es nach McLuhan an den Tag, welches Ausmaß die Vorherrschaft des Intellekts angenommen hat. Sie setzen der Beziehungslosigkeit ein völlig neues Milieu der allseitigen, erdumspannenden Kommunikation entgegen, hatte doch das Schriftmonopol der Gutenberg-Ara als eine Form des Abstrahierens und der Ubersetzung der vielen beim Sprechen mitwirkenden Sinne in einen einzigen Kommunikationsmodus eine "Verarmung " menschlicher Sinnes- und Erkenntniskräfte bewirkt, die nunmehr durch den "elektromagnetischen Raum" in der menschheitsumfassenden „Stammeskultur des auditiven Zeitalters" wieder aufgehoben wird.

In der Tat hat uns die Technik so phantastische, ans Traumhafte grenzende Möglichkeiten allseitiger Kommunikation gebracht, daß es denjenigen, der sie extrapoliert oder nur staunend wahrnimmt, schon davontragen kann. Sicherlich läßt sich die Wirklichkeit aber kaum in das Prokrustes-Bett einer Gutenberg-Ara, was ihr angeblich vorausgeht oder was auf sie folgt, pressen. Die Monokausalität solcher Erklärungsmuster ist irreführend. Dennoch überrascht bei McLuhan immer wieder, wie er im Detail - weniger im Ganzen, wo man ihm überhaupt nicht folgen kann - unser Denken mit dem Blick auf die Kulturentwicklung des Menschen und die unterschiedlichen Kommunikationsformen zu schärfen versteht. Das kann hier nur angedeutet werden und wird auch ersichtlich, wenn wir uns jetzt der Dreiecksbeziehung von Empfänger, Medium und Botschaft nach McLuhan zuwenden.

\section{Heiße und kalte Medien}

McLuhan schreibt: „Der Empfänger partizipiert viel mehr aktiv an der Schaffung seiner Borschaft aus allen Komponenten, die in seine sensorische Welt eindringen, als daß er sich bloß passiv an das angleicht, was der Sender beabsichtigte ${ }^{\alpha 11}$. Die eigentliche Botschaft besteht also in ihrem Gesamteffekt auf den menschlichen Empfänger. McLuhans Satz "The medium is the message" ist somit nicht jenes mechanistische Modell, als das es häufig mißverstanden wird. Noch wird hier die Kommunikation als geradliniger Prozeß geschildert. Vielmehr erweist sie sich abhängig von den sensorischen Korrelationen und den subjektiven Neigungen der Menschen in ihrer gesellschaftlichen Beschaffenheit. Daß die Rezipienten ihrerseits einen aktiven Part spielen und die Medien unterschiedlich "genutzt ${ }^{\text {" }}$ werden, wissen wir inzwischen aus der Wirkungsforschung, von der McLuhan sich in diesem Punkt bestätigt fühlen kann.

Welche Sinnesreize die einzelnen Medien liefern und welche sensorischen Präferenzen sie stimulieren, das hat McLuhan in seiner Klassifizierung von "heißen“ und "kalten“ 
Medien festgehalten. Heiße Medien wie Druck, Schrift, Film liefern spezifische Sinnesreize mit großer Trennschärfe. Sie induzieren automatisch Synästhesie (Umwandlung gegebener Sinnesreize in unterschiedliche Sinnesreaktionen, z. B. Tonempfindung bei hellem Licht) und lassen daher der Vorstellungskraft des Menschen nur wenig Spielraum. Sie wirken "zersplitternd und ausschließend", was - und hier kommt wieder ein weiter Sprung - zu geringem persönlichen Engagement führt, zur Distanzierung. Kalte Medien wie Telefon, Schwarzweiß- und Farbfernsehen liefern spezifische Sinnesreize mit geringer Trennschärfe und induzieren Sinnesreaktionen, die ergänzen, was der Eingabe mangelt. Daher erfordern kalte Medien Vorstellungskraft und bieten ihr viel Spielraum. Sie wirken „integrierend und einschließend“, was zu einem starken persönlichen Engagement führt, zur Partizipation ${ }^{12}$.

Diese Einteilung hat Verwirrung gestiftet. McLuhan ist selbst darauf eingegangen, wie nah "hot" und "cool" - er gebraucht meistens diese Vokabel anstelle von "cold" - beieinanderliegen. Er wählt den Slang-Ausdruck „cool“ für eine Qualität, die den einzelnen stark involviert und in seiner Tiefenstruktur berührt. Eine Photographie, so sagt er, liefert im Regelfall visuell viele Daten und bedarf kaum noch der Ergänzung durch das Auge. Andererseits ist ein Kartoon, der nur umrißhafte und noch auszufüllende Informationen liefert, wie eine Aufforderung an die Sinne, das Ideogramm, Symbol, die "Gestalt" erst herzustellen. Ahnlich beurteilt McLuhan das Fernsehen. Die das Mosaikbild auf dem Fernsehschirm bildenden Lichtpunkte werden vom Auge des Publikums gewissermaßen abgetastet und vom Bewußtsein zu Informationen strukturiert. Beim Fernsehen sei der Zuschauer eigentlich der Bildschirm. Er werde unablässig mit Lichtimpulsen bombardiert, wovon er sich sein "Bild“ macht. Er müsse sich stärker mit allen Sinnen „engagieren " und sei in der Tiefendimension berührt. McLuhan geht es nicht primär um Klassifizierungen, sondern um das Erkennen struktureller Formen und Wirkungen, deren Dynamik er auf das Verhältnis von Mensch, Medium und Botschaft projiziert ${ }^{13}$.

In einem Interview sagte McLuhan, im elektronischen Zeitalter gingen wir auf eine Welt neuer Denk- und Rationalitätsmuster zu. Der Mensch erweise sich nicht nur als vernünftig, wenn er in Kategorien der aristotelischen Ja/Nein-Logik und der distanzierten Objektivität denkt ${ }^{14}$. Für ihn hat der "Kanal ${ }^{\text {“ }}$ des Ohrs eine erheblich größere Tiefenwirkung auf die menschliche Person als die durch das Auge eintretenden Wahrnehmungen. Das strenge Regiment der gedruckten Texte habe das visuelle Sensorium überdiszipliniert und dem Gutenberg-Menschen die Maschinenordnung der Technologie mit ihren Zeittafeln, Gewichten und Maßen aufgezwungen. Mit den elektronischen Medien sei nunmehr die Kultur des auditiven „Kanals“ wieder stärker zum Zuge gekommen.

\section{Wunderbare Welt der Sprache}

Mit seiner Aufmerksamkeit für das Sprachphänomen und den Sinnesreiz des Hörens fühlt sich McLuhan in der Welt der Musiker, Dichter, Maler und Linguisten zu Hause, wo es keine linearen Perspektiven, kein "innen“ und „außen“ gibt - etwa im Dadaismus, Symbolismus, Kubismus -, sondern zwischen der sichtbaren und unsichtbaren Welt Brücken entstehen. So bezeichnet er den Dichter als „Pontifex", und die größte, dem Menschen bekannte Brücke sei Sprechen und Sprache. Mit einem schönen Zitat von T.S. Eliot, den er neben Joyce immer wieder heranzieht, belegt er das Auditive: „Was ich als ,auditive Imagination' bezeichne, ist das Gefühl für Silbe und Rhythmus, das tief unter die bewußten Schichten des Denkens und Fühlens dringt und 
jedes Wort belebt: es ist ein Einsinken in das Primitive und Vergessene, eine Rückkehr zum Ursprung und ein Mitbringen von dort, eine Suche nach dem Anfang und dem Ende. Gewiß, es wirkt durch Bedeutung, bzw. nicht ohne Bedeutungen im üblichen Sinn, und verschmilzt das Alte und Ausgelöschte, und das Platte, das Gegenwärtige, das Neue und Überraschende, die älteste und die zivilisierteste Mentalität ${ }^{\star 15}$.

McLuhan ist von der „wunderbaren Welt der Worte a angezogen. Was er die auditive Präferenz nennt, ist seine Voreingenommenheit für das Medium der Sprache. In dem Roman "Der Verlust“ berichtet Siegfried Lenz von einem Mann, der infolge eines Schlaganfalls plötzlich sein Sprechvermögen einbüßt. Obwohl er weiterhin die Sprache versteht, kann er sich doch nicht mehr mitteilen und begreift, was die moderne Linguistik in Anknüpfung an einen sprachphilosophischen Gedanken Wilhelm von Humboldts damit meint, daß der Mensch sich die Wirklichkeit vor allem durch Sprache erschließt. „Sprachverlust, das ist nicht weniger als Weltverlust", erklärt der Neurologe in dem Roman ${ }^{16}$. Jede Kultur rezipiert "Wirklichkeit" auf ihre Weise und bringt aus der Gesamtheit sensorischer Erfahrungen immer nur einzelne Ausschnitte zur Geltung. Die Wahrnehmungsmuster der Eskimos für das Phänomen "Schnee" sind so differenziert, daß sie zwischen vierzig und fünfzig verschiedene Worte für diese Wirklichkeit vorweisen können.

McLuhans Präferenz für eine Kultur des Auditiven gegenüber einer Kultur des Visuellen läßt viele Fragen offen. Daß das Ohr dem Auge an sensorischem Reichtum überlegen sei, ist schwer beweisbar. Ebenso offen sind Annahmen über das Leseverhalten und inwiefern die phonetische Schrift überhaupt als "visuelles Medium “ klassifizierbar erscheint. Die Kräfte im Menschen, die ein sensorisches Ubergewicht nach dieser oder jener Seite bewirken, sind außerordentlich komplex. Ohne Zweifel haben die jeweiligen Medien mit ihren spezifischen Kommunikationsformen einen bestimmenden Einfluß auf das Kommunikationsverhalten. Aber reicht das zur Herausarbeitung einer epistemologischen Theorie gegenïber den Medien? Über die langfristigen Auswirkungen des Fernsehens auf Bewußtsein und Sensorium des Menschen wissen wir wenig. Daß McLuhan die Aufmerksamkeit darauf lenkte, macht seine Arbeit schon einer Prüfung wert, selbst wenn unsere Fragen auch bereits bei den Prämissen beginnen. McLuhan meint, der Mensch des Westens und der elektronischen Revolution erfahre täglich vor dem Bildschirm durch „die massiven Ausweitungen des zentralen Nervensystems" mittels der elektronischen Kommunikationsmittel eine synästhetisierende Kraft. Ihn fasziniert die elektrische, weltumspannende Simultaneität „im Zeitalter eines alles durchdringenden Bewußtseins", und er sieht die Visionen eines Yeats, Blake oder D. H. Lawrence in Erfüllung gehen. „Es scheint, daß der elektronische Mensch zum Guten oder Schlechten daran geht, die Einheitlichkeit und Integrität des globalen Milieus wiederum als sein natürliches und unabdingbares Erbe zu beanspruchen ${ }^{\alpha 17}$.

\section{Der Mensch selbst ist Botschaft}

Zusammenfassend bleibt erneut festzuhalten, daß viele der Thesen McLuhans unhaltbar sind, soweit er sie nicht schon selbst als phantastische Gedankenspielerei deklariert hat. Unhaltbar ist die von ihm entwickelte Wahrnehmungspsychologie, nach der jedes Medium eine Ausweitung eines unserer Sinne darstellen soll und die Organismus-Analogien absolut gesetzt werden. Unhaltbar ist auch eine so verrückte Idee, daß über das Fernsehmedium, dessen sozialpsychologische Folgen McLuhan ganz falsch eingeschätzt hat, unser Zentralnervensystem selbst erweitert wird und daß damit die Welt sich zu 
einem einzigen Bewußtseinsraum verdichtet, in dem es nunmehr möglich sein soll, daß dieses Medium seiner Struktur nach die Menschen zu Verantwortung, Teilnahme und sozialer Friedfertigkeit anspornt. Schön wär's. In höchstem Maße fragwürdig ist auch der geschichtsphilosophische Ansatz von McLuhan, daß Kulturwandel schlechthin identisch sei mit kommunikativem Wandel. „Mediengeschichte“, schreibt Harry Pross mit Recht, „müßte eine Art Universalgeschichte werden, wenn sie die konstitutive Macht der Kommunikation für die Gesellschaft interpretieren wollte". Die tendenzielle Offenheit von Kommunikation müßte jedoch einen solchen Interpretationsversuch „ins Uferlose ${ }^{\text {eühren }}{ }^{18}$. McLuhan ist dieser Gefahr deutlich erlegen, die ihrer Grenzen bewußte Wissenschaft $\mathrm{zu}$ verwerfen und $\mathrm{zu}$ verkennen, daß Mediengeschichte nicht Kommunikationsgeschichte sein kann ${ }^{10}$.

Positiv bleibt es, daß McLuhan sein Publikum angesichts der "organisierten Skepsis“ einer Wissenschaft, der es ohnehin nur auf die Falsifikation irriger Hypothesen anzukommen scheint ${ }^{20}$, auf eine interdisziplinäre Entdeckungsfahrt nimmt und auf $\mathrm{Zu}-$ sammenhänge verweist, die oft abwegig, aber manchmal auch zutreffend sind. Eine Theorie, die das Ganze unserer Kommunikationsverhältnisse kausal zu erklären imstande wäre, wird es wohl niemals geben - wohl auch niemals geben dürfen, hätte sie doch damit der Wissenschaft ein Machtinstrument an die Hand gegeben, das sie wohl kaum verantworten könnte. Diesen Traum träumte McLuhan vergebens. Eine Theorie, die sich jedoch nicht nur auf das Prinzip der Meßbarkeit beschränkt und deren Interesse nicht nur ein funktionalistisches oder technologisches ist, wird sich gegenüber "Wahrheiten“ des Menschen die Offenheit zu erhalten suchen und sie nicht draußen vor der Tür lassen.

Es ist nicht erstaunlich, daß dieser kanadische Katholik aus einem baptistischen Elternhaus sich von einem Theologen wie Teilhard de Chardin besonders angezogen fühlte. Teilhard läßt die divergierenden Tendenzen der Evolution in der „Noosphäre" eines kosmischen Weltbewußtseins aufgehen ${ }^{21}$. McLuhan erblickt seinerseits in der elektronischen Kommunikation eine Hoffnung, daß der Mensch von der Tyrannei der Maschine freikommt und er die $Z$ weckrationalität nicht für die einzige Erkenntnisweise hält. Er übersieht dabei, daß das Fernsehen auch eine „Maschine“ ist. Aber McLuhan ist dem weitverbreiteten Kulturpessimismus nicht erlegen. In seiner Einschätzung fördert das Zusammenspiel und Aufeinanderprallen von Wahrnehmungsformen im Medium Fernsehen neue Arten des Dialogs und des Bewußtseins: „Der Fernsehteilnehmer ist der Inhalt des Fernsehens. Der Mensch selbst ist der Inhalt und die Botschaft der Medien, die Ausweitungen seiner selbst darstellen. Vor allem aber muß der elektronische Mensch die Wirkungen der von ihm selbst geschaffenen Welt erkennen " ${ }^{\text {"22. }}$.

In einem Interview ist McLuhan gefragt worden, was ihn ursprünglich dazu gebracht habe, sich mit Medien zu befassen und nach den Wirkungen der Medien auf unsere Kultur zu fragen. Er antwortete, für ihn hätten die verschiedenen Möglichkeiten, wie menschliche Erfahrung in unserer eigenen oder in fremden Kulturen zustande kommt, eine gewisse Rolle gespielt, aber seine literarische Arbeit sei der stärkste Beweggrund gewesen. Er fände die Medienanalyse auch deshalb so aufregend, weil die Wirkungen sich auf so viele Menschen erstreckten und es die Konsequenz des elektronischen Zeitalters sei, daß alle mit allen verbunden würden. „Hier hat vielleicht auch mein religiöser Glaube eine Rolle gespielt", fügte McLuhan hinzu“ª 


\section{Anmerkungen}

1 Ulrich Saxer: Messianismus und Wissenschaft bei Marshall McLuhan. in: „Communicatio Socialis“, 1968/2, 91.

2 Heinz Buddemeier: Die Medienphilosophie McLuhans. Voraussetzungen und Folgen, in: "Rundfunk und Fernsehen", 1975/1-2, 20.

3 Winfried B. Lerg: Herbert Marshall McLuhan - Homo Ludens (1911-1980), in: „Publizistik“, 1981/2, 267.

4 Otto B. Roegele: Marshall McLuhan - Prophet der Medien-Ära, in: „Rheinischer Merkur / Christ und Welt", 9. 1. 1981.

"Hintergründige Wortspiele oder "puns", wie James Joyce sie häufig in "Finnegans Wake“ verwendet, werden auch von McLuhan als "Pointen" gern eingeschoben. Für ihn sind das Formen der verbalen Resonanz, „deren Pointe allerorten ist und deren Grenzen das Universum des Verbalen oder der Logos selbst sind". Mit Recht erinnert er daran, daß die Griechen das Wort mit "Mythos" übersetzten.

- Marshall McLuhan: Wohin steuert die Welt? Massenmedien und Gesellschaftsstruktur. Anthologie aus dem Amerikanischen von Heinrich Jelinek, Wien 1978, 43.

7 Ibid., 42.

8 Ibid., 42.

- Marshall McLuhan: Understanding Media: The Extensions of Man, New York 1964, 3.

10 Vgl. Marshall McLuhan with Wilfried Watson: From Cliché to Archetype, New York 1970.

11 McLuhan: Wohin ... a. a. O., 47.

12 Vgl. Marshall McLuhan, Quentin Fiore: The Medium is the Massage: An Inventory of Effects, New York 1967.

13 McLuhan gründet seine Beurteilung des Fernsehens darauf, daß das Fernsehbild datenarm sei, visuell gesehen. Das Fernsehbild bietet einem Beschauer etwa drei Millionen Punkte pro Sekunde. Davon nimmt er nur ein paar Dutzend in jedem Augenblidk auf, um sich daraus „ein Bild zu machen“. Das Fernsehbild verlange also in jedem Augenblick, daß wir die Lücken im Maschennetz durch angestrengte Beteiligung der Sinne „schließen“, die zutiefst kinetisch und taktil sei, weil Taktilität viel eher ein Wechselspiel der Sinne bedeutet als der isolierte Kontakt der Haut mit einem Gegenstand. McLuhan meint, das Fernsehen zwinge den Menschen, das Bild mit den Augen abzutasten, das Auge werde folglich benutzt wie die Hand, nämlich zum Tasten. So glaubt er den Beweis - höchst fragwürdig und weit hergeholt - angetreten zu haben, wir hätten es beim Fernsehen mit einem auditiv-taktilen und nicht mit einem visuellen Medium zu tun.

14 Gerald Emmanuel Stearn (Ed.): McLuhan - Hot \& Cool, A Critical Symposion with a Rebuttal by McLuhan, New York 1967, 270.

15 Zit. nach McLuhan: Wohin ... a. a. O., 74. Vgl. hierzu die ausgedehnten literaturwissenschaftlichen und philosophischen Exkurse in: The Gutenberg Galaxy, Toronto 1962.

10 Siegfried Lenz: Der Verlust, Roman, Hamburg 1981, 122.

17 McLuhan: Wohin ... a. a. O., 200.

18 Harry Pross: Geschichte und Mediengeschichte, in: Erhard Schreiber, Wolfgang R. Langenbucher, Walter Hömberg (Hrsg.): Kommunikation im Wandel der Gesellschaft. Otto B. Roegele zum 60. Geburtstag, Düsseldorf 1980, 31.

$19 \mathrm{Vgl}$. John M. Phelan: Disendhantment. Meaning and Morality in the Media, Hastings House New York, 1980, $115 \mathrm{f}$. - John M. Phelan ist Kommunikationswissenschaftler an der Jesuiten-Universität Fordham, wo McLuhan im akademischen Jahr 1967/68 den angesehenen Albert-Schweitzer-Lehrstuhl für Humanwissenschaften vertreten hat. Phelan unterstreicht die zunehmende Bedeutung McLuhans für die Kommunikationswissenschaften und meint im Unterschied zu herrschenden Auffassungen, McLuhan habe keine Geschichtserklärung geben wollen, sondern Geschichte lediglich „ausgebeutet“ im Dienst der Erkenntnis über die zentrale Rolle der Kommunikationsmedien. $\mathrm{Da}$ es hier noch viele unbestellte Felder der Kommunikationsforschung gibt und die Kategorien "Sinn" und "Moral" nicht einfach ausgegrenzt werden können, weil sie angeblich nicht wissenschaftsfähig seien und als ob Mas- 
senkommunikation ein isoliertes Phänomen bleiben könne, muß einem Denken, das die Massenmedien vornehmlich als technische Einrichtungen sieht, schwer zugänglich sein.

20 Vgl. Saxer: Messianismus a. a. O., 88.

21 Sowohl Jonathan Miller: Marshall McLuhan, The Viking Press New York 1971, wie auch Raymond Rosenthal: McLuhan: Pro and Con, Penguin Books Baltimore 1969, die sich beide sehr gründlich und kritisch mit McLuhan und seiner Medienphilosophie befassen, bringen eine Reihe von Hinweisen auf theologische Quellen und Vorbilder. Aus protestantischer Sicht läßt sich bei McLuhan durchaus "Katholisierendes“ ausmachen. Andere Kritiker haben bei ihm totalitäre Denkstrukturen nachzuweisen gesucht. Vgl. Sidney Finkelstein: Sense and Nonsense of McLuhan, New York 1968. Ob und wie McLuhan, den die kanadischen Bischöfe 1973 als Berater in die Päpstliche Kommission für die soziale Kommunikation entsandten, auf die vatikanische Pastoralinstruktion "Communio et Progressio" eingegangen ist, entzieht sich meiner Kenntnis. McLuhan nennt das "elektrisch erridhtete, unsichtbare und allumfassende Informationsmilieu" ein annäherndes Faksimile des Corpus Christi Mysticum. In der Pastoralinstruktion gibt es einige Denkansätze, die den McLuhan'schen nahestehen könnten, aber nüchterner verfaßt sind.

22 McLuhan: Wohin ... a. a. O., 220.

23 G. E. Stearn a. a. O., 267.

\section{SUMMARY}

The Canadian Professor Marshall McLuhan became famous for his statement that the electronic revolution reduced the world into a "village", and for his equation of message and medium. Prophet or charlatan, that is the question arising in view of his attempted survey, on which it has become very quiet in the meantime. Did he lay down solid foundations for its continuation? He often renounced scorned the "perception of reality" of science. Otto B. Roegele nevertheless speaks of a certain change of scene in the estimation of McLuhan's popular science. Does the new media not have a considerable changing influence on the model of culture and thought? Meanwhile this question has again been raised. McLuhan was an outsider, and his ideas can hardly be summarized. With irritating "methods" he composed his arguments with "facts" from many disciplines. Many of these thesises are certainly not acceptable, but his interdisciplinary discovery encounters sometimes the right points. So, he perceives, for example, that the rationality of functionalism is not the only method of perception. He himself sees the origin of his media work in his literary work. Media analysis was exciting for him, being extended to many, and the electronic era unifying everbody. The author attempts an appreciation of the extremes. But is a definite classification of McLuhan, who died in December 1980, not still to be expected? 


\section{RESUME}

L'affirmation que la révolution électronique rend le monde semblable à un "village“, particulièrement l'équation de media et message rendirent le professeur Marshall McLuhan, canadien, célèbre. Prophète ou charlatan, c'est la question face à son essai de „synthèse“ qui passa presque sous silence. „A-t-il posé des fondements solides pour la poursuite de son oeuvre? La "réalité de la connaissance“ de la science a souvent mis McLuhan dédaigneusement a part. Otto $B$. Roegele parle cependant d'un certain changement de scène dans l'évaluation de la science populaire de McLuhan. Cependant, des effets considérablement transformants ne parlent-ils pas des nouveaux media vers les modèles de pensées et de culture? Cette question est entre-temps, à nouveau, en plein essor. McLuhan était un outsider et ses idées se laissent à peine totaliser. Avec une "méthode" irritante, il réunit ses preuves à partir de "faits réels", tirés de nombreuses disciplines. Un grand nombre de ses thèses sont à coup sûr insoutenables. Son cheminement vers la découverte à travers les différentes disciplines aboutit cependant quelquefois à l'exactitude. Il admet par exemple que la rationalité en soi n'est pas la seule façon d'aboutir à la connaissance. Lui-même, voit l'origine de son travail de media dans son travail littéraire. L'analyse des media fut pour lui excitante par ce que les faits s'appliquaient à beaucoup d'entre eux, et parce que l'époque électronique unit tout à tous. L'auteur essaie de lui rendre hommage, à travers les extrêmes. Mais un dernier classement de McLuhan, décédé avant la fin de l'année, n'est-il pas encore en suspens?

\section{RESUMEN}

La afirmación de que la revolución electrónica convierte el mundo en una „aldea“ y, sobre todo, su comparación entre medios y mensaje hicieron famoso al profesor canadiense Marshall McLuhan. Profeta o dhalatán? Esta es la pregunta en vista de su intentada „visión integral", de la que ahora se habla bien poco. Puso sólidos fundamentos para seguir constmuyendo? McLuhan dejó de lado a menudo la "realidad del conocimiento" científico. Otto B. Roegele habla sin embargo de un cierto cambio en la escena de la valoración de la ciencia popular de McLuhan. Acaso no tienen los nuevos medios una influencia transformante en los módulos clásicos del pensamiento y de la cultura? Este interrogante es de nuevo actual. McLuhan fué un innovador $y$ sus ideas apenas son compendiables. Con irritante "medología" recopiló de "hechos consumados" el material probatorio de muchas disciplinas. Muchas de sus tesis son, sin duda, insostenibles. Pero su viaje exploratorio interdisciplinario termina a menudo en metas exactas. Intuye, por ejemplo, que la racionalidad lógica no es el único modo de conocimiento. El mismo ve en su trabajo literario el origen de su trabajo sobre medios de comunicación. El análisis de los medios era para él apasionante porque tiene efectos en campos varios y la era electrónica vincula a todos con todo. El autor trata de hacer balance entre los extremos. Pero, no está aún pendiente una última evaluación del McLuhan fallecido en diciembre 1980? 